Article

\title{
The Effect of Motion Time of a Scots Pine Single Seed on Mobile Optoelectronic Grader Efficiency: A Mathematical Patterning
}

\author{
Arthur Novikov ${ }^{1, *(\mathbb{D})}$, Michael Drapalyuk ${ }^{1}$, Olga Dornyak ${ }^{1}$, Vladimir Zelikov ${ }^{1}$ and \\ Vladan Ivetić ${ }^{2}$ \\ 1 Mechanical Department, Voronezh State University of Forestry and Technologies named after G.F. Morozov, \\ 8, Timiryazeva, Voronezh 394087, Russia \\ 2 Faculty of Forestry, University of Belgrade, 1, Kneza Višeslava, 11030 Belgrade, Serbia \\ * Correspondence: arthur.novikov@vglta.vrn.ru; Tel.: +7-903-650-84-09
}

Received: 28 August 2019; Accepted: 24 September 2019; Published: 25 September 2019

check for updates

\begin{abstract}
Research Highlights: Forest owners will be able to solve the problem of testing and selection of viable forest seeds on location and save financial, time, and material resources. The possibility of integrating non-destructive quality control and separation functions in a single portable apparatus is extremely promising. The speed of the contemporary optoelectronic grader is limited by the speed of the slowest component-the mechanical system. Background and Objectives: The technological process of forest seed establishment and design of optoelectronic graders is based on a priori mathematical modeling of structural characteristics, taking into account these criteria. Known models of industrial photoseparators are expensive and have a high energy and material consumption not applicable in the field. Laboratory seed analyzers are characterized by a long time exposure, and the overall size and level of climatic performance do not allow them to be used in the field. Consequently, for small amounts of seed treatment, it is necessary to orient the seeds one by one and ensure clear and rapid coordinated actions of optoelectronic and mechanical systems. The main goal of this research is to increase the efficiency of grading forest seeds by patterning the speed of the mobile device. We will answer the following questions. What are effective geometric parameters for the seed pipe? What factors affect the speed of a single seed's movement? Materials and Methods: This study is based on mathematical modeling, taking into account the basic principles of mechanics, using MatLab software. Results: A mechanical model of a single Scots pine seed's motion in different zones of the seed pipe is designed, taking into account air resistance. The effective height of the seed pipe, taking into account the response time of optoelectronic grader systems, is determined. Conclusions: The time and speed of single seed movement through grader systems depends on the seed pipe's height and radius of curvature. Other things being equal, through the use of the same optical scheme with a microprocessor to solve various problems, the compactness of the photodetector scheme allows, if necessary, to upgrade the grader to solve research problems and for use in forestry.
\end{abstract}

Keywords: forest seeds; Pinus sylvestris L.; seed grading; rapid sorter; seed-coat color, seed movement; motion time; mathematical modelling

\section{Introduction}

Drapalyuk and Novikov point out that "the technology of obtaining seed material with specified qualitative characteristics and technical means for its implementation should ensure the allocation of it at the earliest stage of processing of color-seed races, which are the basis for subsequent separation by quantitative characteristics and obtaining forest crops with improved hereditary properties" [1]. Modern 
trends in the separation of forest seeds are aimed at the use of their spectrometric characteristics [2-8], for example, properties of the cross-section of seeds visualized during mechanical scarification $[9,10]$.

Many forestry authorities prescribe minimal requirements in terms of seed quality used in forest restoration, reforestation, and afforestation programs (e.g., Russian Federation, Serbia, Austria). The most commonly used attributes of tree seed quality are: germination (and/or viability), moisture level, health condition, purity, mass of 1000 seeds, and level of genetic diversity [11]. Seed quality, "as a function of seed origin (including level of genetic improvement), seed viability, and nursery performance" [12] have a decisive effect on the success of: (1) long-term storage for operational and gene conservation purposes [11], (2) tree seedling production in forest nurseries [12], (3) direct seeding in the field [13], and especially (4) aerial seeding [14]. One of the usual practices in seed processing prior to sowing or storage is seed grading in terms of size. This technique, aiming to reach a certain level of seed size uniformity, which is required for efficient mechanical sowing, is usually done by sieve graders. However, "this procedure can change the genetic constitution of the whole seed lot, discarding entire families with smaller seed size" [15]. Although there is evidence of a positive effect of seed size on germination and seedling performances in nurseries [Ivetić et al., unpublished data] and in the field [13], seed size is not evidence of a superior genotype [15]. Furthermore, the size and density of a viable seed may not differ from that of non-viable and dead seeds [16]. Since the effect of both seed size and seed-coat color on the performance of Scots pine seedlings is well documented $[17,18]$, it is more expedient to use an optical criterion for seed grading.

Special technological complexes of machine vision are used to separate seeds by spectrometric properties on an industrial scale. They are widely implemented in agriculture and the food industry. Complexes with the same technical capabilities and characteristics vary significantly in price, which largely depends on the country of manufacture. The main players in this market segment in Russia are the companies "Sisort" (about 60\%), "Voronezhselmash" (about 20\%), and other smaller companies (about 20\%). The world market has its leaders, divided into European companies (Petkus, Westrup Inc., Bühler AG, GTA Sensorik GmbH, and others), American (Carter Day International and others), Asian (the Turkish company Akyurek Technology Ltd.), and other. Complexes include blocks of feed of seeds, the collection and processing of the images, and an accurate sorting and management system [19]. Complexes are expensive and have a high energy and material intensity not applicable in the field. Moreover, the sorting unit in almost all cases includes a compressed air receiver, creating an operating pressure of 0.85 to $1 \mathrm{MPa}[19,20]$. We cannot say with sufficient certainty that collisions of small forest seeds with each other and with the walls of the device under the influence of air flow [21] can lead to mechanical damage to the seed envelope or even a violation of the embryo of the seed. Unfortunately, in the modern scientific literature this question is not fully presented.

To study the spectrometric characteristics of forest seeds in the laboratory, scientists use IR analyzers for various purposes and operating principles (FOSS NIRSystems, Inc., Hilleroed, Denmark; FOSS Tecator, Sweden; NIRSystems 6500, Silver Spring, MD USA; Infraspek LLC, S-Pb, Russia etc.). All are characterized by high values of seed exposure time at a sufficiently high resolution.

Overall dimensions and climatic design do not allow them to be used in the field.

Most modern separation devices use a layer-by-layer seed recognition algorithm, which allows for "the reduction of the total execution time" [22] but can lead to "extremely unstable results" [23]. Therefore, for the processing of small volumes of forest seeds it is necessary to orient seeds on one [20] and to provide accurate and fast coordinated actions of optoelectronic [24,25] and mechanical systems [26] with use of a stochastic algorithm [27,28]. At the same time, for precision seed feeding, it is possible to use rollers rotating in opposite directions [29], a pneumatic single dispenser [30], or a robotic arm [22]. For the movement of seeds inside the mobile optoelectronic grader, a transparent vertical seed pipe is used [31].

An optoelectronic grader [24] includes dosing, diagnostic, and grading modules (see Figure 1). The seeds are delivered from the dosing module to the vertical transparent pipeline at a frequency set by the microprocessor. The diameter of the pipeline is equal to the maximum size of the seeds. 
In the optoelectronic module, the luminous flux from the light source enters through the lens and the transparent wall of the pipeline to the surface of the falling seeds. The reflected light flux from the surface of the seeds enters the input of the optical convert group of the reflected signal, and the transmission light flux enters the input of the optical convert group of the transmitted signal. From the outputs of the optical groups, the signals are fed to the input of the electronic group for processing and control. Based on the analysis of the spectral characteristics of the seed, the group generates control signals for the stepper motor rotating the sorting pipeline through the reducer. The motor ensures that its output is brought to a position that coincides with the input of the seed storage cell in which the seeds with optical characteristics coinciding with the characteristics of the sorted seed are located.

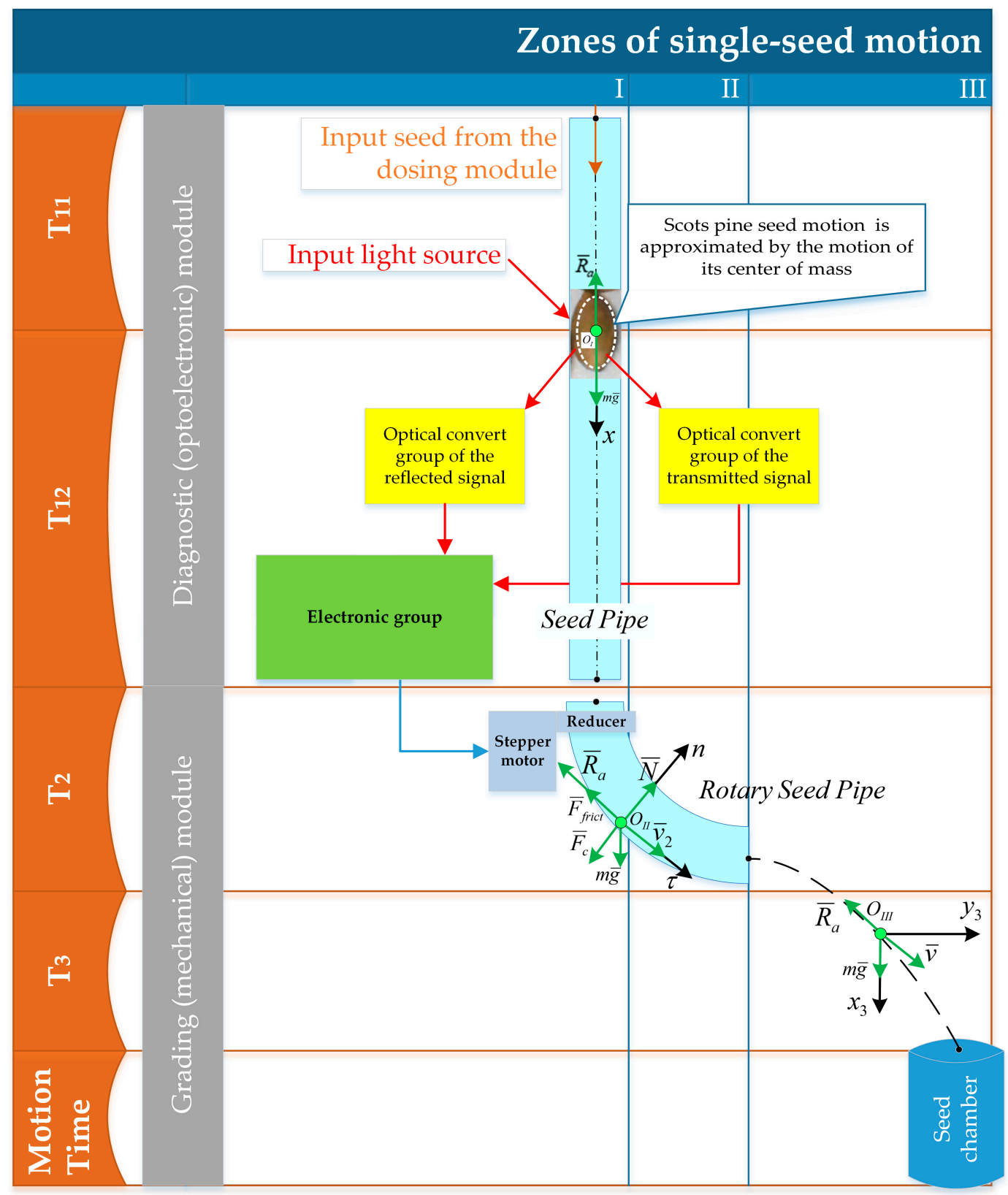

Figure 1. Motion diagram of a single Scots pine seed inside the seed pipe of an optoelectronic grader. For zone I, we establish a one-dimensional Cartesian coordinate system. For zone II, we establish a two-dimensional natural coordinate system. For zone III, we establish a two-dimensional Cartesian coordinate system. 
The advantages of the grader are its high speed, limited only by the speed of the mechanical module, the ability to implement any program seed's analysis and sorting, as well as the ability to use the device in the field [25]. This will save potential customers money, time, and resources for the purchase or transportation of expensive coniferous seeds to seed centers, solving the problem of sorting seeds on location [32].

The grading of pine seeds is a set of physical and mechanical transformations, changes in the motion parameters of single seeds under the action of resistance forces, purposefully carried out in the apparatus. Since the nominal speed of the mobile optoelectronic grader depends on the mechanics of seed movement, it is necessary to determine the time intervals in the characteristic areas. During this time, the seed should have time to pass the diagnosis and be separated into the appropriate receiver. This study also answers the following questions. What should the height of the seed pipe be? What factors affect the speed and time of movement of seeds in the seed pipe?

\section{Materials and Methods}

The object of study was the seeds of Scots pine (Pinus sylvestris L.), the shape of which was approximated by an ellipsoid or spheroid [29]. Seeds were obtained from cones collected in a natural forest stand of the Voronezh region, Russia.

The aim of the study amounted to modeling the movement of a single seed into the mechanical (separation) system of the optoelectronic grader according to the patent [26] developed with the participation of the authors. The principle of grader operation is the interaction of dosing, diagnostic, and grading modules (see Figure 1). A vertically arranged transparent seed pipe receives seeds for separation. Based on the analysis of the spectral characteristics of a single seed obtained at the outputs of the optical unit, the electronic unit generates control signals of a stepper motor rotating a curved seed pipe through the reducer in zone II. Here, it is necessary to bring its output to the position coinciding with the entrance of the chamber for storing separated seeds, in which the seeds with analogous spectrometric characteristics are stored.

The performance parameters of optoelectronic grader systems consist of the performance characteristics of optoelectronic devices from which they are composed. The response time of the optical (diagnostic) system depends on the response time of the photodetectors (up to $10^{-10} \mathrm{~s}$ ). The response time of the electronic system consists of the response time of the multiplexer " $2 \mathrm{~N} \times 1$ " (up to $10^{-9} \mathrm{~s}$ ), analog-to-digital converter (up to $10^{-4} \mathrm{~s}$ ), and microprocessor (up to $10^{-6} \mathrm{~s}$ ), and the response time of the mechanical system depends on the response time of the stepper motor (up to $10^{-3} \mathrm{~s}$ ).

To describe the motion (see Figure 1) of a single seed in a transparent seed conduit, the basic provisions of theoretical mechanics [33] were used, as well as the numerical simulation of motion conditions to solve the problem of determining time. Numerical simulation was performed using the MatLab application software package, version 2010b.

\section{Theoretical Assumptions}

Imagine the movement of a single seed as the movement of its center of mass. The center of mass moves as a material point, in which is concentrated the entire mass of the seed and to which is applied the resultant of the external forces $\bar{R}_{a}$. The movement of seed occurs through three distinct zones (see Figure 1). Consider the initial conditions of motion in each of them.

\subsection{Task Definition}

\subsubsection{The Motion Time}

The total time of movement of a single seed $T$ inside the seed pipe of an optoelectronic grader is the sum of the time of passage in the first $T_{1}$, the second $T_{2}$, and the third $T_{3}$ zones of movement (see Figure 1). In this case, the time of passage in the first zone consists of the sum of the time $T_{11}$ of the seed motion until the moment of optical contact at the point $O_{I}$ and the time $T_{12}$ of the seed motion 
after the moment of optical contact during the operation of the diagnostic module. The total time of movement of a single seed from the beginning of the movement in the pipeline to the end of the movement in the receiver is

$$
T=T_{11}+T_{12}+T_{2}+T_{3} .
$$

Substituting the response time of the optoelectronic grader devices into Equation (1) from the moment of signal detection to the moment of seed departure from the pipeline, we obtain

$$
T_{12}+T_{2}>T_{\text {optical group }}+T_{\text {electronic group }}+T_{\text {stepper motor }}{ }^{-3} \text {. }
$$

For guaranteed response time to the seed image and improvement of the separation process for further calculations, we accept

$$
T_{12}+T_{2}>10^{-3} \text { s. }
$$

\subsubsection{Movement Zone I}

The mathematical description of the law of motion for a single seed in zone I in the one-dimensional Cartesian coordinate system (vertical axis $x$ ) is as follows:

$$
m \ddot{x}=m g-R_{a x},
$$

where

$m$ is the seed mass in $\mathrm{kg}$;

$\ddot{x}$ is the acceleration $a_{x}$ of the center of mass of the seed in $\mathrm{m} \cdot \mathrm{s}^{-2}$;

$g$ is the gravity acceleration, $g=9,81 \mathrm{~m} \cdot \mathrm{s}^{-2}$;

$R_{a x}=0.5 c_{x} \rho S_{s} v^{2}$ is the resultant of the resistance forces, in that $c_{x}$ is the dimensionless drag coefficient of the seed in the air; $\rho$ is the seed density, $\mathrm{kg} \cdot \mathrm{m}^{-3} ; S_{S}$ is the square of the seed midsection, $\mathrm{m}^{2} ; v$ is the speed of the mass center of the seed, $v=\dot{x}, \mathrm{~m} \cdot \mathrm{s}^{-1}$.

The solution to Equation (1) with initial conditions

$$
t=0\left\{\begin{array}{l}
x=0 \\
\dot{x}=0
\end{array}\right.
$$

gives $\dot{x}=x(t)$.

The equation of the form $x(t)=H_{1}$ will determine the:

- $\quad$ time $T_{1}$ of passage in zone I with height $H_{1}$;

- height $H_{1}$ of zone I at a given time $T_{1} x\left(T_{1}\right)=H_{1}$.

The function allows you to track the speed of the center of mass of a single seed at all points of zone I, including $x=H_{1}\left(v_{1}\right) ; \dot{x}\left(T_{1}\right)=v_{1}$.

We obtain the initial velocity $v_{1}$ of a single seed in zone II, namely

$$
\left\{\begin{array}{c}
\dot{s}(0)=v_{1} \\
s(0)=0
\end{array} .\right.
$$

\subsubsection{Movement Zone II}

The mathematical description of the law of motion for a single seed in zone II in the natural coordinate system ( $\tau$ - and $n$-axes) is as follows:

$$
\begin{gathered}
m \ddot{s}=-\mu N-0.5 c_{x} \rho S_{s} v^{2}+m g \cos \varphi, \\
m \frac{v^{2}}{R}=N-m g \sin \varphi,
\end{gathered}
$$


where

$\ddot{s}$ is the acceleration of the mass center of seed in $\mathrm{m} \cdot \mathrm{s}^{-2}$;

$\mu$ is the coefficient of friction;

$\mathrm{N}$ is the normal force, $\mathrm{N}$;

$\varphi$ is the angle of deviation of the linear velocity vector from the horizontal in rad;

$R$ is the curvature radius that best approximates the seed pipe's curve at point $O_{I I}$ in $\mathrm{m}$.

From Equation (8), we have

$$
N=m \frac{v^{2}}{R}+m g \sin \frac{S}{R}
$$

From Equation (7), by substituting $N$, it follows that

$$
m \ddot{s}=-\mu m\left(\frac{v^{2}}{R}+g \sin \frac{S}{R}\right)+m g \cos \frac{S}{R}-0.5 c_{x} \rho S_{s} v^{2},
$$

or

$$
m \ddot{s}+v^{2}\left[0.5 c_{x} \rho S_{s}+\mu \frac{m}{R}\right]+\mu m g \sin \frac{S}{R}-m g \cos \frac{S}{R}=0 .
$$

Thus:

- $\quad$ the Equation (11) with initial conditions (6) gives a solution $s=s(t)$;

- the equation of the form $s(t)=\frac{1}{2} \pi R$ will determine the time $T_{2}$ during which a single seed will pass zone II;

- the equation of the form $s(t)=\frac{1}{2} \pi R$ will determine the radius of curvature of the seed pipe for a given time $T_{2}$;

- $\quad \dot{s}(t)$ is the speed of a single seed for all $t$, including the speed at the end of the corner $\dot{s}\left(T_{2}\right)=v_{2}$.

\subsubsection{Movement Zone III}

The mathematical description of the law of motion for a single seed in zone III in the two-dimensional Cartesian coordinate system ( $x_{3}$ - and $y_{3}$-axes) is as follows:

$$
\left\{\begin{array}{c}
m \ddot{x}_{3}=m g-R_{a x_{3}} \\
m \ddot{y}_{3}=-R_{a y_{3}}
\end{array} .\right.
$$

From Equation (12) with initial conditions of the form

$$
\left\{\begin{array} { l } 
{ x _ { 3 } ( 0 ) = 0 } \\
{ y _ { 3 } ( 0 ) = 0 }
\end{array} \quad \left\{\begin{array}{c}
\dot{x}_{3}(0)=v_{2} \\
\dot{y}_{3}(0)=0
\end{array},\right.\right.
$$

it will be possible to determine the time $T_{3}$ during which a single seed will pass zone III.

\subsection{Reduction of Equations to a Dimensionless Form}

Reduction of equations to dimensionless form usually allows one to significantly reduce the number of parameters. We introduce the typical parameters $t_{t p}, l_{t p}, m$,

$$
x^{*}=\frac{x}{l_{t p}}, t^{*}=\frac{t}{t_{t p}} .
$$


3.2.1. Zone I

We give Equation (4) in a dimensionless form:

$$
\begin{gathered}
\frac{m l_{t p}}{t_{t p}^{2}} \frac{d^{2} x^{*}}{d t^{* 2}}=m g-0.5 c_{x} \rho S_{s} \frac{l_{t p}^{2}}{x_{t p}^{2}}\left(\frac{d x^{*}}{d t^{*}}\right)^{2} \\
\frac{d^{2} x^{*}}{d t^{* 2}}=\frac{g t_{t p}^{2}}{l_{t p}}-\frac{0.5 c_{x} \rho S_{s} l_{t p}}{m}\left(\frac{d x^{*}}{d t^{*}}\right)^{2}
\end{gathered}
$$

Denote in equation (16)

$$
\frac{g t_{t p}^{2}}{l_{t p}}=g^{*}, \frac{0.5 c_{x} \rho S_{s} l_{t p}}{m}=K_{1}^{2}
$$

Then

$$
\frac{d^{2} x^{*}}{d t^{* 2}}=g^{*}-K_{1}^{2}\left(\frac{d x^{*}}{d t^{*}}\right)^{2}
$$

under initial conditions

$$
\left\{\begin{array}{c}
\mathrm{x}^{*}(0)=0 \\
\frac{\mathrm{dx} \mathrm{x}^{*}}{\left.\mathrm{dt}\right|^{*}=0} \mathrm{t}^{*}=0
\end{array}\right.
$$

\subsubsection{Zone II}

We give Equations (7) and (8) in a dimensionless form when $s^{*}=\frac{s}{l_{t p}}$.

$$
\begin{gathered}
\frac{m l_{t p} \ddot{S}^{*}}{t_{t p}^{2}}+\dot{S}^{* 2} \frac{l_{t p}^{2}}{x_{t p}^{2}}\left[0.5 c_{x} \rho S_{s}+\mu \frac{m}{R}\right]+\mu m g \sin \left(\frac{s^{*} l_{t p}}{R}\right)-m g \cos \left(\frac{s^{*} l_{t p}}{R}\right)=0 ; \\
\ddot{S}^{*}+\dot{S}^{* 2}\left(K_{1}^{2}+\frac{\mu l_{t p}}{R}\right)+\frac{g t_{t p}^{2}}{l_{t p}} \sin \left(\frac{s^{*} l_{t p}}{R}\right)-\frac{g t_{t p}^{2}}{l_{t p}} \cos \left(\frac{s^{*} l_{t p}}{R}\right)=0 .
\end{gathered}
$$

Denote

$$
g^{*}=\frac{g t_{t p}^{2}}{l_{t p}}, \quad R^{*}=\frac{R}{l_{t p}} \quad \text { and } K_{2}^{2}=K_{1}^{2}+\frac{\mu}{R^{*}} \frac{0.5 c_{x} \rho S_{s} l_{t p}}{m}
$$

Then

$$
\dddot{S}^{*}+\dot{S}^{* 2} K_{2}^{2}+g^{*}\left[\sin \left(\frac{S^{*}}{R^{*}}\right)-\cos \left(\frac{S^{*}}{R^{*}}\right)\right]=0
$$

under initial conditions

$$
\left\{\begin{array}{c}
S^{*}(0)=0 \\
\dot{S}^{*}(0)=\frac{v_{1} t_{t p}}{l_{t p}}=v_{1}^{*}
\end{array} .\right.
$$

\subsubsection{Zone III}

We give equation $(\Delta)$ in a dimensionless form

$$
\left\{\begin{array}{c|c}
\ddot{x}_{3}^{*}=g^{*}-K_{1}^{2} v^{*} v_{x_{3}}^{*} & x_{3}^{*}=\frac{x_{3}}{l_{t p}} \\
\ddot{y}_{3}^{*}=0-K_{1}^{2} v^{*} v_{y_{3}}^{*} & y_{3}^{*}=\frac{y_{3}}{l_{t p}}
\end{array}\right\}
$$


under initial conditions

$$
\left\{\begin{array}{c}
\dot{x}_{3}^{*}(0)=v_{2}^{*} \\
x_{3}^{*}(0)=0 \\
\dot{y}_{3}^{*}(0)=0 \\
y_{3}^{*}(0)=0
\end{array} .\right.
$$

After transformations of the Equation (25) taking into account $v=\sqrt{v_{x_{3}}^{* 2}+v_{y_{3}}^{* 2}}=\sqrt{\dot{x}_{3}^{* 2}+\dot{y}_{3}^{* 2}}$, we obtain

$$
\left\{\begin{array}{l}
\ddot{y}_{3}^{*}+K_{1}^{2} \sqrt{\dot{x}_{3}^{* 2}+\dot{y}_{3}^{* 2}} \dot{x}_{3}^{*}=g^{*} \\
\ddot{y}_{3}^{*}+K_{1}^{2} \sqrt{\dot{x}_{3}^{* 2}+\dot{y}_{3}^{* 2}} \dot{y}_{3}^{*}=0
\end{array} .\right.
$$

\section{Result and Discussion}

The analysis shows that Equation (18) can be solved analytically, but Equations (23) and (27) require numerical study with initial conditions (solution of a Cauchy problem).

With the help of the Matlab application software package version 2010b, numerical patterning was carried out for two extreme positions: maximum and minimum possible seed parameter. Constant values were seed geometry, seed density, the square of the middle section, the coefficient of friction, and the coefficient of flow. The variation was subjected to the geometrical parameters of the seed pipe: the seed pipe's height $h_{1}$ in zone $\mathrm{I}$, the radius of curvature $R$ of the seed pipe in zone II, and the height $\mathrm{h}_{3}$ of the seed fall in zone III. As a result, the characteristic of the change in the time $T$ of movement of the seed in the above areas and its speed (see Figure 2) was obtained.

In the first zone (see Figure 2a), the time of seed movement depends mainly on the air resistance, and with values of seed pipe height from 0.2 to $0.5 \mathrm{~m}$, it fits perfectly into the conditions (3) and (6). The speed of movement of the seed at the maximum physical and mechanical parameters of the seed is significantly higher than the speed at the minimum parameters, but when the height of the seed pipe is from 0.1 to $0.2 \mathrm{~m}$, the movement time of such seeds is the same. Therefore, it is desirable to choose the height of the seed pipe in this area based on the purpose of the device; for the mobile version it is advisable to lay a height of $0.1-0.2 \mathrm{~m}$.

In the second zone (see Figure $2 b$ ), the speed of seed movement at values of the radius of curvature of the seed pipe greater than $0.02 \mathrm{~m}$ does not depend on the physical and mechanical parameters of the seed. In the same range, there is a decrease in the time of motion due to the additional force of friction on the seed pipe walls. Therefore, we consider it appropriate to recommend that when designing a separation module device, the radius of curvature of the seed pipe in the second zone should be in the range of 0.01 to $0.02 \mathrm{~m}$.

In the third zone (see Figure 2c), there is a characteristic region of change in seed velocity in the 0.05 to $0.06 \mathrm{~m}$ range of the height of the fall of the seed. The reduced in the velocity of a single seed having a maximum size is explained by the larger values square $S_{S}$ of its midsection and the resultant $\bar{R}_{a}$ of the external forces. At the same time, the fastest seed movement time from 0.1 to $0.2 \mathrm{~s}$ is observed at the zone. When designing the geometric parameters of the third section of the device, it is advisable to take into account the height of the fall to $0.05 \mathrm{~m}$ and be guided by the design features of the separating compartments. Moreover, in order to reduce the time of movement of the seed and as a consequence reduce the time of separation and increase the accuracy and performance of the device, it is necessary in future to consider the exclusion of the rotational motion of the seed pipe on zone II. 
$T_{1}, \mathrm{~s}$

(a)

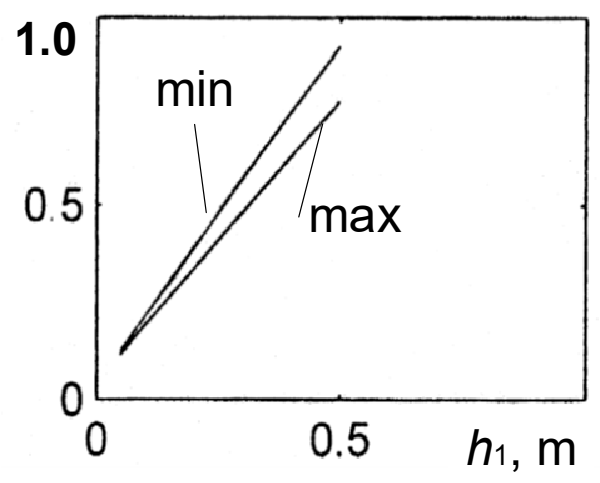

$T_{2}, \mathrm{~s}$

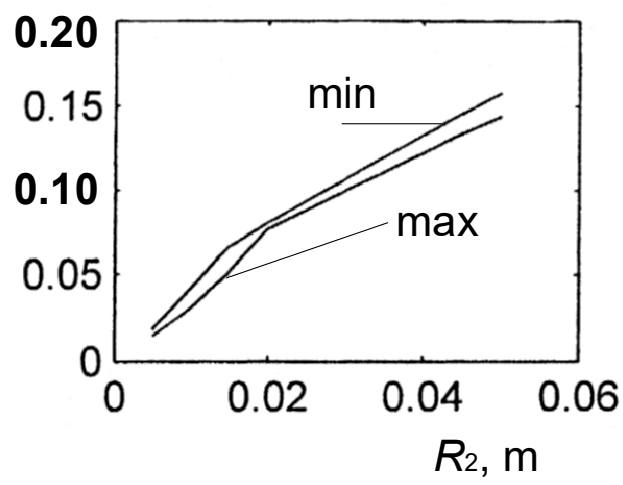

$T_{3}, \mathrm{~S}$

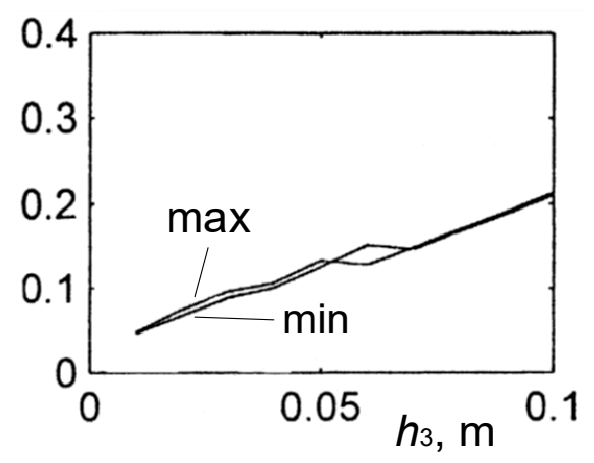

$v_{1}, \mathrm{~m} \mathrm{~s}^{-1}$

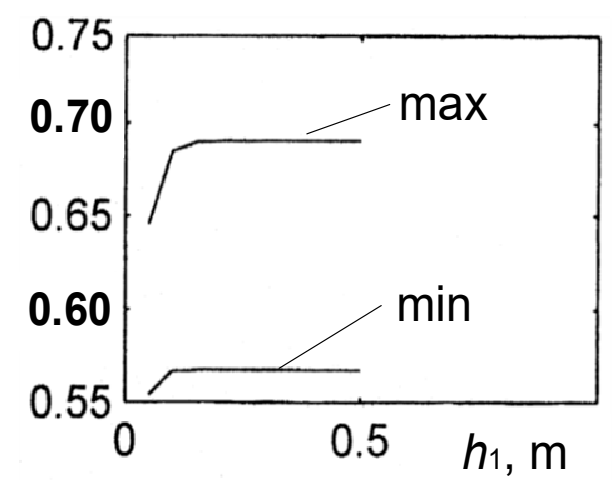

$v_{2}, \mathrm{~m} \mathrm{~s}^{-1}$

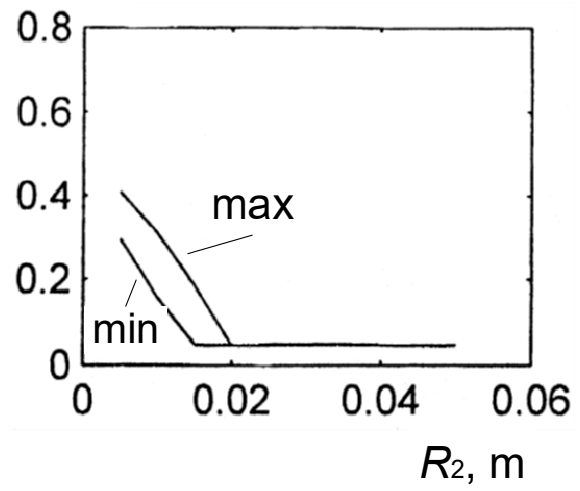

$v_{3}, \mathrm{~m} \mathrm{~s}^{-1}$

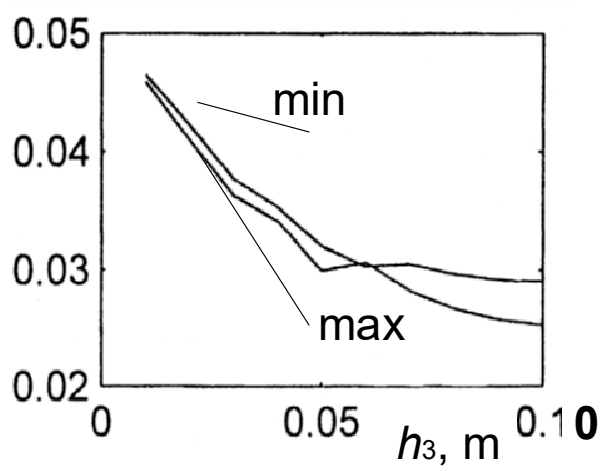

Figure 2. Influence of the height of the seed pipe $h_{1}$ in zone I (a), the radius of curvature $R$ of the seed pipe in zone II (b), and the height $h_{3}$ of the seed fall in zone III (c) on the time $\left(T_{1}, T_{2}\right.$, and $\left.T_{3}\right)$ and speed $\left(v_{1}, v_{2}\right.$, and $\left.v_{3}\right)$ of the movement of a single seed. The maximum (max) line is for the maximum size and weight parameters of the pine seed (the single seed mass $m_{\max }=8.0 \times 10^{-6} \mathrm{~kg}$; the square of seed midsection $S_{S}=8.5 \times 10^{-6} \mathrm{~m}^{2}$ ), the minimum ( $\mathrm{min}$ ) line is for the minimum values $\left(m_{\min }=5.6 \times 10^{-6} \mathrm{~kg} ; S_{S}=3.2 \times 10^{-6} \mathrm{~m}^{2}\right)$. The height $h$ and radius $R$ of the pipeline are limited to 0.5 $\mathrm{m}$ and $0.1 \mathrm{~m}$ due to compliance with the requirements for small dimensions of the grader.

\section{Conclusions}

The efficiency of all grader systems is based on the time of passing a single seed, which should be greater than $10^{-3} \mathrm{~s}$. 
The time and speed of movement of a single seed through a grader system depends on the geometric parameters of the mechanical system - the height of the seed pipe (from 0.1 to $0.2 \mathrm{~m}$ ) and the radius of curvature (from 0.01 to $0.02 \mathrm{~m}$ ).

The strength of air resistance due to the small height of the seed pipe does not have a significant effect on the increase in the movement time of a single seed.

Thus, through the use of the same optical scheme with a microprocessor, the compactness of the photodetector scheme allows, if necessary, to upgrade the grader to solve research problems and for field use in forestry.

Author Contributions: Conceptualization, A.N., O.D., and V.I.; methodology, A.N., O.D., M.D., and V.I.; validation, A.N., V.I., and V.Z.; formal analysis, A.N. and O.D.; investigation, M.D. and V.Z.; resources, A.N. and V.I.; data curation, A.N., O.D., V.Z., and V.I.; writing—original draft preparation, O.D., A.N., M.D., V.Z., and V.I.; writing—review and editing, A.N., M.D., O.D., and V.I.; visualization, A.N. and O.D.; supervision, A.N.

Funding: This research received no external funding.

Conflicts of Interest: The authors declare no conflict of interest.

\section{References}

1. Sokolov, S.V.; Novikov, A.I. Development tendency of sowing air operating technology by unmanned aerial vehicles in artificial reforestation. For. Eng. J. 2017, 7, 190-205.

2. Farhadi, M.; Tigabu, M.; Pietrzykowski, M.; Danusevičius, D.; Odén, P.C. Application of near infrared spectroscopy for authentication of Picea abies seed provenance. New For. 2017, 48, 629-642. [CrossRef]

3. Farhadi, M.; Tigabu, M.; Stener, L.-G.; Oden, P.C. Feasibility of visible plus near infrared spectroscopy for non-destructive verification of European x Japanese larch hybrid seeds. New For. 2016, 47, 271-285. [CrossRef]

4. Ambrose, A.; Lohumi, S.; Lee, W.-H.; Cho, B.K. Comparative nondestructive measurement of corn seed viability using Fourier transform near-infrared (FT-NIR) and Raman spectroscopy. Sens. Actuators B Chem. 2016, 224, 500-506. [CrossRef]

5. Dumont, J.; Hirvonen, T.; Heikkinen, V.; Mistretta, M.; Granlund, L.; Himanen, K.; Fauch, L.; Porali, I.; Hiltunen, J.; Keski-Saari, S.; et al. Thermal and hyperspectral imaging for Norway spruce (Picea abies) seeds screening. Comput. Electron. Agric. 2015, 116, 118-124. [CrossRef]

6. Farhadi, M.; Tigabu, M.; Odén, P. Near Infrared Spectroscopy as non-destructive method for sorting viable, petrified and empty seeds of Larix sibirica. Silva Fenn. 2015, 49, 1-12. [CrossRef]

7. Novikov, A.I.; Saushkin, V.V. Infrared range spectroscopy: The study of the pine seed coat parameters. For. Eng. J. 2018, 8, 30-37.

8. Novikov, A.I. Visible wave spectrometric features of scots pine seeds: The basis for designing a rapid analyzer. IOP Conf. Ser. Earth Environ. Sci. 2019, 226, 012064. [CrossRef]

9. Przybyło, J.; Jabłoński, M. Using Deep Convolutional Neural Network for oak acorn viability recognition based on color images of their sections. Comput. Electron. Agric. 2019, 156, 490-499. [CrossRef]

10. Kaliniewicz, Z.; Tylek, P. Influence of Scarification on the Germination Capacity of Acorns Harvested from Uneven-Aged Stands of Pedunculate Oak (Quercus robur L.). Forests 2018, 9, 100. [CrossRef]

11. Ivetić, V. Handbook on Seed Production, Seedling Production and Afforestation [on Serbian]; University of Belgrade, Faculty of Forestry: Belgrade, Serbia, 2013.

12. Ivetić, V.; Novikov, A.I. The role of forest reproductive material quality in forest restoration. For. Eng. J. 2019, 9, 56-65.

13. Grossnickle, S.C.; Ivetić, V. Direct Seeding in Reforestation-A Field Performance Review. Reforesta 2017, 4, 94-142. [CrossRef]

14. Novikov, A.I.; Ersson, B.T. Aerial seeding of forests in Russia: A selected literature analysis. IOP Conf. Ser. Earth Environ. Sci. 2019, 226, 012051. [CrossRef]

15. Ivetić, V.; Devetaković,J.; Nonić, M.; Stanković, D.; Šijačić-Nikolić, M. Genetic diversity and forest reproductive material from seed source selection to planting. iForest Biogeosci. For. 2016, 9, 801-812. [CrossRef] 
16. Tigabu, M.; Daneshvar, A.; Jingjing, R.; Wu, P.; Ma, X.; Odén, P.C. Multivariate Discriminant Analysis of Single Seed Near Infrared Spectra for Sorting Dead-Filled and Viable Seeds of Three Pine Species: Does One Model Fit All Species? Forests 2019, 10, 469. [CrossRef]

17. Novikov, A.I.; Ivetić, V. The effect of seed coat color grading on height of one-year-old container-grown Scots pine seedlings planted on post-fire site. IOP Conf. Ser. Earth Environ. Sci. 2019, 226, 012043. [CrossRef]

18. Novikov, A.I.; Ivetić, V. The effect of seed size grading on seed use efficiency and height of one-year-old container-grown Scots pine (Pinus sylvestris L.) seedlings. Reforesta 2018, 6, 100-109. [CrossRef]

19. Yi, C.W.; Li, W.X. Study on Automatic Control Method of Seeds Grading Device. Trans. Chin. Soc. Agric. Mach. 2005, 8, 15-23.

20. Clohessy, J.W.; Pauli, D.; Kreher, K.M.; Buckler, V.; Edward, S.; Armstrong, P.R.; Wu, T.; Hoekenga, O.A.; Jannink, J.-L.; Sorrells, M.E.; et al. A Low-Cost Automated System for High-Throughput Phenotyping of Single Oat Seeds. Plant Phenome J. 2018, 1. [CrossRef]

21. Affleck, S.; Affleck, L. Apparatus for Sorting Seeds According to Color. U.S. Patent 4,946,046, 7 August 1990.

22. Arya, S. Development of a Seed Analyzer using the Techniques of Computer Vision. Int. J. Distrib. Parallel Syst. 2012, 3, 149-155. [CrossRef]

23. Zivoli, R.; Gambacorta, L.; Piemontese, L.; Solfrizzo, M. Reduction of Aflatoxins in Apricot Kernels by Electronic and Manual Color Sorting. Toxins 2016, 8, 26. [CrossRef] [PubMed]

24. Sokolov, S.V.; Novikov, A.I. New optoelectronic systems for express analysis of seeds in forestry production. For. Eng. J. 2019, 9, 5-13.

25. Albekov, A.U.; Drapalyuk, M.V.; Morkovina, S.S.; Vovchenko, N.G.; Novikov, A.I.; Sokolov, S.V.; Novikova, T.P. Express Analyzer of Seed Quality. Russian Patent 2,675,056, 14 December 2018.

26. Albekov, A.U.; Drapalyuk, M.V.; Morkovina, S.S.; Vovchenko, N.G.; Novikov, A.I.; Sokolov, S.V.; Novikova, T.P. Device for Seeds Sorting. Russian Patent 2,682,854, 21 March 2019.

27. Kucherenko, P.A.; Sokolov, S.V. Solution of the problem of identifying structures of discrete stochastic objects based on the minimum posterior error criterion of distribution densities. Autom. Control Comput. Sci. 2016, 50, 28-36. [CrossRef]

28. Balascio, C.C.; Misra, M.K.; Johnson, H.P. Stochastic modeling of granular flow in seed sorting. Math. Comput. Model. 1988, 11, 523-527. [CrossRef]

29. Novikov, A.I. Disc Separators in Forest Seed Production [in Russian Diskovye separatory Semyan v Lesohozyajstvennom Proizvodstve]; VSUFT: Voronezh, Russia, 2017.

30. Xing, H.; Wang, Z.; Luo, X.; Zang, Y.; Yang, W.; Zhang, M.; Ma, Y. Design of an active seed throwing and cleaning unit for pneumatic rice seed metering device. Int. J. Agric. Biol. Eng. 2018, 11, 62-69. [CrossRef]

31. Albekov, A.U.; Drapalyuk, M.V.; Morkovina, S.S.; Novikov, A.I.; Vovchenko, N.G.; Sokolov, S.V.; Novikova, T.P. Seed Sorting Device. Russian Patent 2,687,509, 14 May 2019.

32. Drapalyuk, M.V.; Novikov, A.I. Device for sorting forest seeds on quality basis. Curr. Res. Areas XXI Century Theory Pract. 2018, 6, 145-149. (In Russian)

33. Liu, J. Lecture Notes on Theoretical Mechanics; Springer: Singapore, 2019; ISBN 978-981-13-8034-1.

(C) 2019 by the authors. Licensee MDPI, Basel, Switzerland. This article is an open access article distributed under the terms and conditions of the Creative Commons Attribution (CC BY) license (http://creativecommons.org/licenses/by/4.0/). 